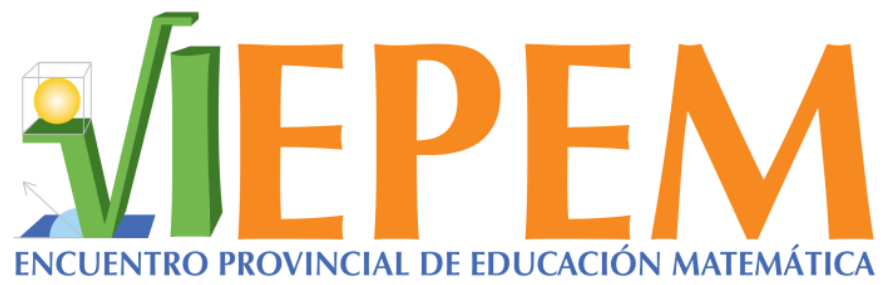

VI Encuentro Provincial de Educación Matemática.

27 al 29 de setiembre, 2017. Puntarenas, Costa Rica.

\title{
La noción de idoneidad didáctica como herramienta para la reflexión de la clase de matemática
}

\author{
Yuri Morales-López \\ ymorales@una.cr \\ Universidad Nacional \\ Costa Rica \\ Daniela Araya Román \\ damaarro2708@gmail.com \\ Universidad Estatal a Distancia \\ Costa Rica \\ Vicenç Font Moll \\ vfont@ub.edu \\ Universitat de Barcelona \\ España
}

\begin{abstract}
Resumen
Poder realizar una reflexión de lo que ocurre en la clase de matemática es una competencia que debe poseer el profesor en servicio. Esta actividad de reflexión es compleja y más si no se cuenta con una estructura que permita ordenar y seleccionar la información que podría ser relevante. En este taller se propone una serie de actividades vinculadas con la observación de episodios de aula y posibles estrategias para realizar un análisis didáctico. En general, se espera que el participante conozca algunas herramientas del Enfoque Ontosemiótico que podrían permitir un análisis de las situaciones que se presentan.
\end{abstract}

Palabras clave: Enfoque Ontosemiótico, análisis didáctico, episodios de clase, educación matemática.

\section{Introducción}

Costa Rica aprobó un nuevo currículo para toda la educación matemática preuniversitaria y esto tiene implicaciones en muchos sectores. Este cambio requiere un

Taller

Morales-López, Y.; Araya, D. y Font, V. (2017). La noción de idoneidad didáctica como herramienta para la reflexión de la clase de matemática. En Y. Morales-López, M. Picado, R. Gamboa, C. Martínez, M. Castillo y R. Hidalgo (Eds.), Memorias del VI Encuentro Provincial de Educación Matemática, Costa Rica, 2017 (pp. 49-51). Heredia: Universidad Nacional. ISBN: 9789968-9661-5-3. DOI: http://dx.doi.org/10.15359/epem.6.13 
profesorado con ciertas capacidades y habilidades que le permitan cumplir la expectativa que el programa de matemáticas encierra (Morales-López, 2017). Una de las principales tareas que tiene el profesor de matemáticas es valorar la pertinencia de las actividades y procesos que está realizando en la clase. Esta tarea no solo vincula un planeamiento adecuado, sino también, se sujeta al estudio sistemático de lo que ocurre durante el proceso (Morales y Font, 2017). El Enfoque Ontosemiótico (Godino, Batanero y Font, 2007) proporciona algunas herramientas que permiten abordar esta tarea. En especial, a través de la noción de idoneidad didáctica del modelo de Conocimientos y Competencias Didáctico Matemáticos (CCDM) del profesor de matemáticas (Godino, Batanero, Font y Giacomone, 2016; Breda, Pino y Font, 2017), se puede estimular la organización, selección y valoración de información que pueda ser relevante.

\section{Metodología del taller}

Este taller es de tipo participativo y está organizado en cuatro etapas.

Etapa 1: Se presentará un episodio de clase y se solicitará que se explique brevemente las situaciones que son de interés sobre la clase desarrollada sin considerar guías o pautas.

Etapa 2: Se trabajará en la presentación del concepto de idoneidad didáctica en el CCDM, criterios de idoneidad didáctica y la pauta de Font (2015).

Etapa 3: Se le presentará un nuevo episodio de clase y, con el uso de la pauta, se pedirá valorar una de los criterios de idoneidad didáctica.

Etapa 4: Se comentará en grupo sobre la utilidad de las herramientas presentadas y sobre la reflexión de lo que ocurre en el aula.

\section{Resultados esperados}

Se espera que el participante del taller: 1) conozca sobre los criterios de idoneidad; 2) realice una valoración inicial de las situaciones presentadas en episodios seleccionados; 3 ) realice una valoración elemental de estos episodios basado en los criterios de idoneidad basados en la pauta de Font (2015).

Reconocimientos: actividad elaborada en el marco de los proyectos de investigación: EDU2015-64646-P (MINECO/FEDER, UE) y SIA 0005-14 (UNA, Costa Rica). 


\section{Referencias}

Breda, A., Pino-Fan, L., \& Font, V. (2017). Meta didactic-mathematical knowledge of teachers: criteria for the reflection and assessment on teaching practice. Eurasia Journal of Mathematics, Science \& Technology Education, 13(6), 1893-1918. doi: 10.12973/eurasia.2017.01207a

Font, V. (2015). Pauta de análisis y valoración de la idoneidad didáctica de procesos de enseñanza y aprendizaje de la matemática [Guideline for the analysis and assessment of the didactical suitability of the mathematics teaching and learning processes]. Unpublished manuscript. Departamento de Didáctica de las CCEE y la Matemática, Universitat de Barcelona.

Godino, J. D., Batanero, C. y Font, V. (2007). The onto-semiotic approach to research in mathematics education. ZDM. The International Journal on Mathematics Education, 39 (1-2), 127-135. Doi http://dx.doi.org/10.1007/s11858-006-0004-1

Godino, J.D., Batanero, C., Font, V. y Giacomone, B. (2016). Articulando conocimientos y competencias del profesor de matemáticas: el modelo CCDM. En C. Fernández, J. L. González, F. J. Ruiz, T. Fernández y A. Berciano (Eds.), Investigación en Educación Matemática XX (pp. 288-297). Málaga: SEIEM.

Morales, Y.; Font, V. (2017). Análisis de la reflexión presente en las crónicas de estudiantes en formación inicial en educación matemática durante su periodo de práctica profesional. Revista ACTA SCIENTIAE, 19(1), 122-137. Disponible en http://www.periodicos.ulbra.br/index.php/acta/article/view/2975/2280

Morales-López, Y. (2017). Costa Rica: The Preparation of Mathematics Teachers. En A. Ruiz (Ed.), Mathematics Teacher Preparation in Central America and the Caribbean (pp. 39-56). Springer International Publishing. Recuperado de http://link.springer.com/chapter/10.1007/978-3-319-44177-1_3

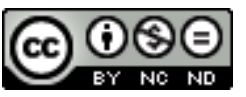

Esta obra está bajo una licencia de Creative Commons Reconocimiento-NoComercialSinObraDerivada 4.0 Internacional. 